\title{
EDITORIAL
}

\section{A rewarding journey}

Josephine E. Sciortino, MA

Past Editorial Director, CUAJ

Cite as: Can Urol Assoc J 2015;9(11-12):367

http://dx.doi.org/10.5489/cuaj.3503

Published online December 14, 2015

Pour la version française: cuaj.ca
Dear readers,

After nine years of service to the Canadian Urological Association (CUA), I am leaving to take a position at the Cancer Research Society as Director of Communications and Marketing.

It has been a pleasure to serve as Editorial Director for the Canadian Urological Association Journal (CUA))!

Since its inception nine years ago, CUAJ has gone through many changes. It started as a quarterly journal in 2007 and is now monthly. We started with a mere five papers in the queue to now receiving more than 650 papers for consideration per year!

The journal has had many advocates and ambassadors throughout the years, starting with inaugural Editor, Dr. Laurence Klotz, and 2006-2007 CUA President, Dr. Luc Valiquette. Dr. Armen Aprikian was Editor-in-Chief for a year, while Dr. Klotz was CUA President, and now CUAJ's Editor-in-Chief role is in the capable hands of Dr. Rob Siemens, going into his second term.

Establishing CUA/ with Dr. Klotz and Dr. Valiquette at the very beginning and completing my term with Dr. Siemens has been the highlight of my professional career so far. As I move on, the lessons I've learned at the CUA, personal and professional, will remain with me and guide my steps moving forward.

CUAJ experiences the many challenges faced by medical journals, including lack of resources, lack of advertising revenues to cover the costs of running the journal, and late reviewers. I think, however, that CUAJ has a stronger hand than most; it has the support of CUA members and Board of Directors. CUAJ has become more than just a journal for peer-reviewed articles. It has become a home for Canadian urologic research, a home for residents to share their experiences and challenges, and a home for both academic and community urologists to add to the growing body of urologic literature.

CUAJ will be left in good hands - with Denise Toner continuing to be the robust Advertising Manager and new Managing Editor, Adriana Modica, who I know will be an excellent CUA team player and manager for the journal. In their capable hands and with the direction of Dr. Rob Siemens and his Editorial Board, CUA/ will continue to thrive.

Readers, reviewers, authors: Thank you for being a part of my journey at CUAJ! 